\title{
Las celebraciones del III y IV Centenario del Quijote en Hispanoamérica a través de la prensa española de 1905 y $2005^{*}$
}

\author{
María Ángeles Chaparro Domínguez ${ }^{* *}$
}

El IV Centenario de la publicación de la primera parte de El ingenioso hidalgo don Quijote de la Mancha ${ }^{1}$, celebrado en 2005, se tradujo en España en el surgimiento repentino de numerosas actividades conmemorativas, en las que primaba la cantidad antes que la calidad (Lucía, 2006: 271). La efeméride se convirtió en un elemento comercial, tanto para los organizadores de las actividades conmemorativas, fueran entes públicos o empresas privadas, como para la propia prensa, que no dejó pasar la oportunidad de enriquecerse con la venta de objetos relacionados con la figura del hidalgo manchego (Chaparro, 2009: 312). Grandes grupos mediáticos, como PRISA, se convirtieron en patrocinadores oficiales de la efeméride (Chaparro, 2008).

En el presente estudio vamos a realizar un análisis de cómo se vivió el IV Centenario del Quijote fuera de nuestras fronteras pero sin abandonar nuestro idioma, en concreto, en los países hispanoamericanos, tomando como fuente la prensa española. Para completar este análisis, también estudiaremos qué sucedió cien años atrás, es decir, cómo fue la cobertura que hicieron los principales periódicos españoles de 1905 de las actividades conmemorativas que tuvieron lugar ese año en Hispanoamérica, con motivo del III Centenario de la publicación de la primera parte del Quijote.

* El presente artículo parte de algunas de las ideas planteadas en la tesis doctoral La construcción social de la cultura: el Quijote como icono de las representaciones mediáticas de las celebraciones del III y IV Centenario, dirigida por Joaquín María Aguirre y María Pilar Vega y defendida el 24 de junio de 2011 en la Universidad Complutense.

** Universidad Rey Juan Carlos.

1. A partir de ahora aludiremos a la obra como el Quijote, para abreviar su título. Lo escribimos en cursiva para distinguirlo del personaje, en letra redonda. 
De este modo, nuestros objetivos son estudiar el tratamiento periodístico que brindaron los diarios a las celebraciones del otro lado del Atlántico, cuáles fueron dichos homenajes a través de los ojos de la prensa $\mathrm{y}$, además, trataremos de extraer el valor simbólico que adquirió en cada época la figura del hidalgo manchego, un mito universal. Una vez que hayamos explicado la metodología que hemos seguido en nuestro estudio, como paso previo a nuestro análisis nos detendremos brevemente en conocer cómo y cuándo llegó por primera vez la popular novela de Cervantes a Hispanoamérica y cuáles fueron allí sus primeras manifestaciones, tanto en la literatura como en el terreno social. Eso nos permitirá ser conscientes de la importancia que tuvo allí la obra desde sus orígenes.

\section{Metodología}

El campo de estudio de esta investigación abarca dos etapas históricas diferentes, con el fin de poder establecer comparaciones. En concreto, hemos analizado las informaciones periodísticas — artículos de opinión, noticias, crónicas, entrevistas y reportajes — de los años 1904, 1905, 2004 y 2005 relativas al III y IV Centenario del Quijote, respectivamente. Tenemos presente que las efemérides quijotescas tuvieron lugar en 1905 y 2005. No obstante, hemos ampliado el periodo de estudio a un año menos en cada caso con el objetivo de estudiar cómo fue preparando la prensa a la sociedad ante la efeméride que llegaría en unos cuantos meses.

En el caso de 1905, hemos estudiado El Imparcial, El Liberal, La Correspondencia de España, ABC, La Vanguardia, La Voz de Galicia, Las Provincias, El Liberal de Sevilla, El Correo de Guipúzcoa y La Crónica, de Guadalajara. Hemos seleccionado periódicos de especial relevancia en la época, tanto madrileños - El Imparcial, El Liberal o La Correspondencia de España- como periódicos de otras regiones, con el fin de contar con un amplio abanico geográfico de textos periodísticos.

En cuanto al año 2005, hemos escogido once diarios: cuatro de información general, seis regionales en papel y un diario provincial digital. Los generalistas son El País, El Mundo, ABC y La Vanguardia. El primero, por ser el diario de información general de mayor tirada del país ${ }^{2}$; El Mundo por ser el segundo en cuanto a importancia y difusión ${ }^{3}$; en el caso de $A B C$ y $L a$ Vanguardia, por su importancia y por haber sido seleccionados ya en 1905 .

2. De enero a diciembre de 2010, el diario El País registró un promedio de difusión de 370.080 ejemplares, según la Oficina de Justificación de la Difusión (http://www.ojd.es/OJD/Portal/diarios ojd/ 4DOSpuiQo1Y FOivPcLIIA).

3. El diario El $\bar{M}$ Mndo registró un promedio de difusión entre enero y diciembre de 2010 de 284.091 ejemplares, según la Oficina de Justificación de la Difusión (http://www.ojd.es/OJD/Portal/ diarios_ojd/_4DOSpuiQo1Y_FOivPcLIIA). 
En el caso de los regionales, hemos estudiado La Voz de Galicia, Córdoba, Levante-El Mercantil Valenciano, Las Provincias, La Tribuna de Ciudad Real y Deia. En cuanto a la selección concreta de estos medios, además de tener en cuenta su tirada, hemos intentado que no pertenecieran a los grupos mediáticos dueños de las grandes cabeceras (El País, El Mundo y $A B C$, es decir, PRISA, Unidad Editorial y Vocento, respectivamente) ya que, de hacerlo, muchas informaciones serían exactamente las mismas.

Además, hemos procurado que tampoco fueran del mismo grupo los medios regionales seleccionados, algo que reducía las opciones de búsqueda, ya que existen numerosos grupos editoriales que copan las cabeceras provinciales. Con el fin de enriquecer el estudio, hemos incluido un diario digital de Castilla-La Mancha, La Crónica de Guadalajara, por ser la comunidad en la que vivió Don Quijote.

En total, entre los periódicos de 1905 y 2005, hemos estudiado los textos periodísticos que tratan sobre el III y el IV Centenario del Quijote de 21 cabeceras repartidas por toda España.

\section{DESEMBARCO DEL QUIJOTE EN EL NUEVO MUNDO}

La popular novela de Cervantes llegó a Hispanoamérica en el mismo año que se publicó por primera vez en España, en 1605, junto con otras mercancías que ocupaban las bodegas de los barcos que arribaban al Nuevo Mundo. Resulta imposible establecer con exactitud cuántos libros llegaron en estas primeras remesas, pero lo cierto es que su volumen fue considerable 4 . De la librería de Alcalá de Henares de Juan Sarriá salieron numerosos ejemplares que se repartieron en México y Perú con gran éxito (Zulueta, 1984: 145).

Las primeras ediciones de la primera parte impresas en el Nuevo Mundo no se realizarán hasta bien entrado el siglo XIX. La primera tuvo lugar en la ciudad de México en 1833, más de una década después de que la antigua colonia consiguiera la independencia de España. Le siguieron Valparaíso (1863), Montevideo (1880) y Argentina (1904) (Montero, 2006: 323).

En la primera mitad del siglo XVIII aparecen algunas obras hispanoamericanas que evidencian la presencia de la novela de Cervantes en el continente $^{5}$. Nos referimos a La Quijotita y su prima (1818-1819), del mexicano José Joaquín Fernández de Lizardi, o El cristiano errante (1847), de Antonio

4. Las investigaciones de Francisco Rodríguez Marín, José Torre Revello, Irving A. Leonard y Guillermo Lohmann Villena sobre las listas de libros registrados para ser enviados al Nuevo Mundo han permitido saber que un alto número de las primeras ediciones de la primera parte del Quijote fue destinado para su venta colonial. Son listas incompletas que recogen las siguientes cifras: Rodríguez Marín contabilizó 346 ejemplares; Lohmann Villena, 361, y Leonard, 433 (Montero, 2006: 319).

5. En el siglo XVII no hayamos influencias cervantinas en los escritores hispanoamericanos, salvo el caso excepcional del poeta argentino Luis de Tejeda (1604-1680), en cuya obra tanto Guillermo Díaz-Plaja como Ricardo Rojas ven huellas de Cervantes (Montero, 1992: 135). 
José Irisarri, de Guatemala (Montero, 1992: 134). A finales del siglo XIX y principios del XX encontramos diferentes obras que vienen a ser imitaciones parciales de algunos elementos del Quijote (Zulueta, 1984: 148). Ejemplos de este tipo de obras serían Semblanzas caballerescas o Las nuevas aventuras de Don Quijote de la Mancha (1886), del cubano Luis Otero Pimentel; Capítulos que se le olvidaron a Cervantes: ensayo de imitación de un libro inimitable (1895), del ecuatoriano Juan Montalvo; Don Quijote en América (1905), del venezolano Tulio Febres Cordero; Escenas de la andante españolería (1913), de Mariano Sánchez de Enciso; La jofaina maravillosa: agenda cervantina (1922), del argentino Alberto Gerchunoff, y Las brasas del libro (1976), del también argentino Federico Peltzer.

Además de en el mundo literario, la huella de la popular novela de Cervantes se puso de manifiesto por primera vez en las fiestas populares celebradas en diferentes ciudades de México y Perú desde el siglo XVII, que retrataban al hidalgo manchego como un loco que producía risas, así como en representaciones teatrales posteriores de algunos de sus capítulos, como la que tuvo lugar el 28 de diciembre de 1794 en la ciudad de México, cuando se representó la adaptación teatral del episodio de las Bodas de Camacho, cuyo autor fue Juan Meléndez Valdés (Montero, 1992: 136-138) ${ }^{6}$.

\section{LAS CELEBRACIONES DE HISPANOAMÉRICA EN LA PRENSA ESPAÑOLA DE 1905}

El III Centenario del Quijote en Hispanoamérica apenas se vio reflejado en la prensa española de la época ${ }^{7}$. Resulta curioso que, pese a compartir el mismo idioma y haber mantenido una estrecha relación colonizadora durante más de cuatro siglos, apenas encontramos textos referidos a cómo se vivió la efeméride en el continente americano. De los diez periódicos analizados de 1905, sólo en cinco de ellos - El Imparcial, El Liberal, Las Provincias, La Correspondencia de España y El Liberal de Sevilla - se tratan los homenajes en Hispanoamérica y de forma muy breve. Parecen olvidarse de las celebraciones La Voz de Galicia, La Vanguardia, El correo de Guipúzcoa, $A B C$ y La Crónica.

6. La citada obra de Meléndez Valdés, una comedia musical llamada Las bodas de Camacho el Rico, obtuvo en 1784, diez años antes de que se representase en México, el premio de la villa de Madrid con motivo del nacimiento de los infantes Carlos y Felipe y el «ajuste definitivo de la paz» (Meléndez, 1974).

7. La escasa cobertura que se brindó en España a las actividades hispanoamericanas está en la línea de lo que ocurrió con las celebraciones en otros países, tan cercanos como Portugal, que no aparecieron en la prensa española. Como muestra de estas celebraciones vecinas, podemos observar la publicación de esta obra: Miguel de Cervantes Saavedra (1905). Del Ingenioso Hidalgo Don Quijote de la Mancha: Tricentenario de sua primeira edição: Sessão commerantiva pela Academia Real das Sciencias de Lisboa em 9 de Maio de 1905. Lisboa: Por Ordem de na Typographia da Academia. 
Cuba es el país más mencionado en los diarios, con cinco informaciones que tratan sobre las celebraciones en la isla ${ }^{8}$. Después encontramos Argentina, Honduras y El Salvador, con un texto cada uno ${ }^{9}$. Por último, aparece una información que se refiere a las celebraciones de varios países hispanoamericanos (Guatemala, Chile, Argentina, Perú y México) y que denuncia la inexistencia de este tipo de iniciativas en Ecuador ${ }^{10}$.

En el caso de Cuba, según aparece en la prensa citada, el Diario de la Marina organizó un concurso de estudios críticos sobre la novela con motivo del III Centenario. Más que cubano, este medio es un periódico español, dirigido por el también español Nicolás Rivero, pues, según el periodista de $L a$ Correspondencia de España que escribe la crónica que anuncia el evento ${ }^{11}$, dicho diario «está consagrado a defender en Cuba los intereses españoles y mantener vivo el amor de los cubanos a su antigua Metrópoli». Según el periodista, además de homenajear la novela, la iniciativa pretende «avivar en los cubanos el culto a las glorias indiscutibles de España».

La entrega de galardones de dicho diario fue cubierta por El Liberal ${ }^{12}$ y Las Provincias ${ }^{13}$. La crónica en cuestión es prácticamente idéntica en ambos medios, por lo que entendemos que fue escrita por la misma persona, algo difícil de comprobar puesto que ninguna de ellas aparece con su correspondiente firma. A dicho evento, celebrado en el teatro Tacón de La Habana, asistieron el entonces presidente de la República, Tomás Estrada Palma, sociedades españolas, miembros del Ateneo y de otras entidades cubanas. Según dichos diarios, Bustamante ${ }^{14}$ habló de la unión de Cuba con España, pese a su independencia en 1898.

\footnotetext{
Nunca estuvieron unos y otros [españoles y cubanos] tan unidos como ahora que se ven separados [...]. Con motivo de la celebración de este centenario, Cuba ha dado muestras de ser uno de los pueblos más cultos de la América Latina y, por consiguiente, de los que más honran a la madre España ${ }^{15}$.
}

8. «El 'Quijote' en Cuba», en La Correspondencia de España, 25/02/1905, p. 2; «El Centenario en la Habana», en El Liberal de Sevilla, 25/02/1905, p. 2; «El Centenario en la Habana», en El Liberal, 04/06/1905, p. 2; «El centenario del 'Quijote' en la Habana», en Las Provincias, 13/03/1905, p. 1; «El centenario del 'Quijote' en la Habana», en Las Provincias, 05/06/1905, p. 1.

9. «El Centenario del 'Quijote' en la República Argentina», en El Imparcial, 29/03/1905, p. 3; «El Centenario en Honduras», en El Imparcial, 28/05/1905, p. 2; «Fiestas cervantinas en San Salvador», en El Liberal, 09/05/1905, p. 2.

10. «El centenario del 'Quijote' en América»», en Las Provincias, 21/02/1905, p. 1.

11. «El 'Quijote' en Cuba», en La Correspondencia de España, 25/02/1905, p. 2.

12. «El Centenario en la Habana», en El Liberal, 04/06/1905, p. 2.

13. «El centenario del 'Quijote' en la Habana», en Las Provincias, 05/06/1905, p. 1.

14. Antonio Sánchez de Bustamante y Sirvén fue un conocido jurista cubano, que promovió la existencia de una normativa común americana sobre el derecho internacional privado. Entre otros cargos, fue nombrado juez en 1921 de la Corte Permanente de Justicia Internacional y fue el primer presidente de la Academia Nacional de Artes y Letras de Cuba,

(http://www.britannica.com/EBchecked/topic/86359/Antonio-Sanchez-de-Bustamante-y-Sirven).

15. «El Centenario en la Habana», en El Liberal, 04/06/1905, p. 2. 
Observamos, por tanto, cómo, pese a que no han transcurrido ni diez años desde que la colonia consiguió su ansiada independencia, tras una cruenta guerra de tres años, parece que en el ánimo de los cubanos, o por lo menos en el de Bustamante, no existe odio o resentimiento hacia la antigua metrópoli sino más bien respeto, gratitud e incluso, podríamos decir, admiración.

En Honduras, por su parte, celebraron la efeméride el día 5 de mayo. El jefe de Estado del país, el general Bonilla, calificó el acto como un «justo homenaje a la memoria de España y de su hijo esclarecido, el más grande y el más admirado de todos los tiempos y naciones $\gg{ }^{16}$. El periodista que escribe la crónica alaba sin tapujos las actividades hondureñas, entre las que se encuentra el acuerdo de creación de un teatro llamado Miguel de Cervantes ${ }^{17}$ : «Manifestaciones de este género demuestran el espíritu de solidaridad hispana que anima a los pueblos americanos y no puede menos de regocijar el alma de los que hablamos el mismo idioma en que se escribió la inmortal obra» ${ }^{18}$.

En Argentina se llevó a cabo una velada literaria en el Teatro Olimpo de La Plata ${ }^{19}$, mientras que en El Salvador, su capital San Salvador cobijó diferentes actividades ${ }^{20}$ : concurso de carrozas, decoración e iluminación de edificios, concierto de música española, baile infantil con trajes cervantinos, inauguración de un monumento de Cervantes, edición popular de la novela, fuegos artificiales, elevación de globos aerostáticos, batalla de flores, banquetes y reparto de folletos conmemorativos. El Diario del Salvador promovió, por su parte, un concurso literario.

El diario valenciano Las Provincias, por su parte, reproduce un fragmento de El Grito del Pueblo, de Guayaquil (Ecuador), donde un periodista de dicho diario se queja de que instituciones culturales como la Academia Ecuatoriana, el Liceo de la Juventud y el Círculo Juan Montalvo, y los intelectuales de su país, entre los que cita a Carlos Carbo, César Borja o Rafael María Arizaga, no estén preparando ningún homenaje al Quijote, tal y como ha ocurrido en Guatemala, Chile, Argentina, Perú y México ${ }^{21}$. De estos cinco países, sólo aparecen en la prensa española las actividades conmemorativas de uno de ellos: Argentina.

Asimismo, parece que los citados Cuba, Argentina, Honduras, El Salvador, Guatemala, Chile, Perú y México no fueron los únicos países hispanohablantes americanos que festejaron el III Centenario. Según la Crónica del Centenario del Don Quijote de Miguel Sawa y Pablo Becerra (1905: 556), a esta lista debemos añadir Nicaragua, Bolivia, Colombia, Costa Rica, Paraguay, Uruguay y

16. «El Centenario en Honduras», en El Imparcial, 28/05/1905, p. 2.

17. El teatro, en Tegucigalpa, inaugurado en 1915, se llamó finalmente Teatro Nacional Manuel Bonilla. Entre los intelectuales que solicitaron la construcción del edificio en 1905 al general Bonilla, destacan Rómulo Ernesto Durón, Luis Landa Escobar o Froylán Turcios, todos ellos miembros del comité organizador de los actos conmemorativos del III Centenario del Quijote

(http://www.scad.gob.hn/index.php?option=com_content\&task=view\&id=39\&Itemid=84.)

18. «El Centenario en Honduras», en El Imparcial, 28/05/1905, p. 2.

19. «El Centenario del 'Quijote' en la República Argentina», en El Imparcial, 29/03/1905, p. 3

20. «Fiestas cervantinas en San Salvador», en El Liberal, 09/05/1905, p. 2

21. «El centenario del 'Quijote' en América», en Las Provincias, 21/02/1905, p. 1. 
Venezuela. De hecho, según la Enciclopedia Universal Ilustrada (1908-1930: 1379), celebraron el III Centenario un total de 212 ciudades hispanoamericanas.

En cuanto al valor simbólico que adquirió el personaje del Quijote en las celebraciones hispanoamericanas de 1905, a tenor de lo leído en los escasos artículos periodísticos que trataron sobre estas celebraciones, podemos afirmar que, en general, se vio en el hidalgo manchego una clara unión con la antigua metrópoli, un nexo entre las dos orillas del Atlántico. Se sintió por la novela una profunda admiración, que estaba por encima de los odios políticos y que dejaba atrás las costosas y sangrientas independencias logradas décadas atrás. El Quijote se concibió en 1905 como un hijo de España, de la madre España, pero a la vez como un hermano querido y universal.

\section{LAS CELEBRACIONES DE HISPANOAMÉRICA EN LA PRENSA ESPAÑOLA DE 2005}

En lo que se refiere al IV Centenario, el número de textos periodísticos relativos a las celebraciones en Hispanoamérica fue mucho mayor al de 1905 pero, no obstante, resultó reducido ${ }^{22}$ si tenemos en cuenta la abrumadora cantidad de información periodística que se publicó sobre la efeméride en este segundo periodo $^{23}$. De todos los diarios analizados, en tres de ellos, Deia, Levante-EMV y La Crónica de Guadalajara, no encontramos ninguna información sobre esta materia.

22. En total, encontramos 47 textos en 2004 y 2005 que tienen como protagonistas al Quijote y las celebraciones de su IV Centenario en Hispanoamérica.

23. A modo de ejemplo, en nuestra citada tesis doctoral contabilizamos en el diario El País un total de 230 textos periodísticos referentes al IV Centenario en 2004 y 2005. Por esa razón, consideramos que 47 informaciones sobre Hispanoamérica en los once diarios analizados de este periodo resultan escasas en su contexto. 
El que más importancia le concedió fue La Tribuna de Ciudad Real ${ }^{24}$, con un total de 13 textos publicados ${ }^{25}$, seguido de El País, con $12^{26}$, Córdoba, con siete $^{27}$, y $A B C$, con $\operatorname{seis}^{28}$. Después se situaron La Voz de Galicia, con tres

24. La Tribuna de Ciudad Real fue el diario que más textos publicó sobre el IV Centenario, con un total de 810 informaciones. Este dato explica que también sea el medio que recoge un mayor volumen de textos sobre las actividades quijotescas en Hispanoamérica.

25. «José Bono visita Guanajuato, corazón cervantino de América», en La Tribuna de Ciudad Real, Redacción, 20/02/2004, p. 33; «José Bono ofrece el apoyo de CLM a la afición 'cervantina' de Guanajuato», en La Tribuna de Ciudad Real, Redacción, 22/02/2004, p. 28; «Educación apuesta por revivir las hazañas de El Quijote en las aulas de España e Iberoamérica», en La Tribuna de Ciudad Real, Sergio Ramírez, 12/10/2004, p. 30; «La XX Ruta Quetzal enarbolará la bandera del Quijote por toda América», en La Tribuna de Ciudad Real, Sergio R. Nombela, 19/11/2004, p. 32; «Un pueblo de Argentina trata de recuperar dos joyas del Quijote que le fueron robadas», en La Tribuna de Ciudad Real, Efe, 30/12/2004, p. 51; «Una joven de 17 años gana en Argentina un certamen gracias a Cervantes y su obra», en La Tribuna de Ciudad Real, Redacción, 14/02/2005, p. 28; «La región participa en los actos del IV Centenario en la ciudad mejicana de Guanajuato», en La Tribuna de Ciudad Real, 06/03/2005, p. 27; «Valverde: 'Es un honor que 'El Quijote' tenga un museo como el de Guanajuato'», en La Tribuna de Ciudad Real, Redacción, 07/03/2005, p. 25; «Una visión del IV Centenario desde el otro lado del Atlántico», en La Tribuna de Ciudad Real, Hilario L. Muñoz, 12/07/2005, p. 9; «La Paz celebrará los 400 años de la llegada del Quijote a América», en La Tribuna de Ciudad Real, Redacción, 15/08/2005, p. 25; «Castilla-La Mancha y Guanajuato estrechan lazos sobre 'El Quijote'», en La Tribuna de Ciudad Real, Redacción, 28/11/2005, p. 23; «Castilla-La Mancha y México celebran juntos el IV Centenario», en La Tribuna de Ciudad Real, Redacción, 03/12/2005, p. 14; «CLM y México podrían colaborar para conmemorar la segunda parte de El Quijote», en La Tribuna de Ciudad Real, Redacción, 04/12/2005, p. 26.

26. «El 'Quijote' de la RAE inicia su andadura en Rosario», en El País, J. A. R., 19/11/2004; «México difundirá el 'Quijote' popular entre las comunidades indígenas», en El País, Juan Jesús Aznávez, 25/11/2004; "Colombia, Bolivia y Honduras festejan el centenario del 'Quijote'», en El Pais, Agencias, 12/12/2004; «La Feria de Guadalajara se suma al centenario del 'Quijote'», en El País, Efe, 17/02/2005; «Y Cervantes se va a América», en El País, César Antonio Molina, 01/03/2005; «España reinicia su relación con Cuba a través del 'Quijote'», en El País, Mauricio Vicent, 24/03/2005; «El Gobierno de México regala el 'Quijote' a un millón de maestros», en El País, Francesc Relea, 15/04/2005; «Hugo Chávez regalará un millón de ejemplares del 'Quijote'», en El País, AFP, 18/04/2005; «La Feria de Buenos Aires dedica su maratón de lectura al 'Quijote'», en El Pais, Efe, 22/04/2005; «Ocho compañías de Iberoamérica ofrecen su visión teatral del 'Quijote'», en El País, K. Cabrera, 17/06/2005; «El 'Quijote' centra la Feria del Libro de Paraguay», en El Pais, Efe, 04/07/2005; «Un Quijote para Fox», en El País, 02/12/2005.

27. «Hispanistas americanos inician actos cervantinos», en Córdoba, Efe, 28/09/2004, p. 58; «Colombia proclama el año del Quijote», en Córdoba, 12/12/2004, p. 70; «El Ballet de Cuba homenajea al 'Quijote'», en Córdoba, Europa Press, 08/01/2005, p. 47; «Policías mexicanos deberán leer 'El Quijote'», en Córdoba, Efe, 21/02/2005, p. 42; «El Quijote, el libro más vendido en Bogotá», en Córdoba, 03/05/2005, p. 51; «Artistas mexicanos homenajean al Quijote», en Córdoba, Efe, 14/09/2005, p. 75; «España desembarca en México con 'El Quijote’», en Córdoba, Efe, 10/10/2005, p. 32.

28. «La RAE prepara con las 21 Academias de la Lengua Española un Quijote que valdrá menos de diez euros», en $A B C$, A. Astorga y N. Pulido, 15/06/2004, p. 56; «El Quijote convoca congresos y exposiciones en ciudades españolas y extranjeras», en $A B C$, Tulio Demicheli, 02/12/2004, p. 53; «El Quijote del IV Centenario, el libro más vendido en la Feria de Guadalajara», en $A B C$, M. Cascante, 06/12/2004, p. 51; «Don Quijote en América», en $A B C$, Lisandro Otero, 22/01/2005, p. 63; «Entrega de 50.000 libros de 'El Quijote' al presidente colombiano», en $A B C, 13 / 07 / 2005$, p. 45; «Don Quijote, en un lugar de la Feria de Guadalajara», en $A B C$, M. Cascante, 30/11/2005, p. 63. 
informaciones $^{29}$, y El Mundo ${ }^{30}$, La Vanguardia ${ }^{31}$ y Las Provincias ${ }^{32}$, con dos textos cada uno de ellos. Resulta curioso que un diario de la talla de El Mundo apenas dedique dos textos a la cobertura hispanoamericana de la efeméride quijotesca. Destacaremos a continuación, de forma resumida, las cuestiones más interesantes recogidas en este medio centenar de informaciones de los diarios citados.

Podemos afirmar que la gran aportación del continente americano hispanohablante al IV Centenario fue la colaboración de sus 19 Academias de la Lengua $^{33}$ en la edición popular del Quijote, enmarcada en la Asociación de Academias de la Lengua Española, y editada por Alfaguara.

La edición, cuya iniciativa partió de Honduras durante el XII Congreso de la Asociación de Academias de la Lengua Española celebrado durante los días 12 y 15 de noviembre de 2002 en Puerto Rico, fue dirigida por Francisco Rico, prologada por Mario Vargas Llosa e incluyó reflexiones de Francisco Ayala, Martín de Riquer, José Manuel Blecua, Guillermo Rojo, José Antonio Pascual, Margit Frenk y Claudio Guillén. La obra recoge al final un glosario de más de seis mil acepciones, incluyendo voces, refranes y frases proverbiales.

Además de esta edición popular, otra de las aportaciones de los países hispanohablantes de América a la efeméride fue que, coincidiendo con el hecho de que 2005 fue el Año Iberoamericano de la Lectura, el Quijote se convirtió en el invitado de honor de muchas de las ferias del libro del continente americano, como la de Guadalajara (México), Buenos Aires (Argentina) o Paraguay. Estas acciones no fueron fruto de la casualidad. En octubre de 2004, se reunió en Madrid el Comité de Honor de la Comisión del IV Centenario, formado por el presidente del Gobierno, José Luis Rodríguez Zapatero, y los veinte ministros de Cultura de los países hispanohablantes ${ }^{34}$. En esa reunión

29. «Zapatero invita a Iberoamérica a una celebración integradora del 'Quijote'», en La Voz de Galicia, Miguel Lorenci, 28/10/2004, p. 54; «La ‘cumbre’ de la lengua española dará inició al año del 'Quijote'», en La Voz de Galicia, Redacción, 07/11/2004, p. 56; «El Teatro de la Zarzuela presenta con entusiasmo en México su programa sobre el 'Quijote'», en La Voz de Galicia, Efe, 18/10/2005, p. 50.

30. «Los países hispanohablantes se vuelcan con 'El Quijote'», en El Mundo, Enma Rodríguez, 29/10/2004; «El Quijote se viste de zarzuela en la capital cervantina de Latinoamérica», en El Mundo, Quico Alsedo, 22/10/2005.

31. «La crítica americana aplaude la nueva versión del Quijote», en La Vanguardia, Efe, 04/01/2004, p. 38; «Policías mexicanos, obligados a leer 'El Quijote’», en La Vanguardia, 22/02/2005, p. 48 .

32. «Bambalina Titelles triunfa en Lima con su 'Quijote'», en Las Provincias, Efe, 04/06/2005, p. 76; «El Ballet Nacional de Cuba regresa a Sagunt a escena con 'Don Quijote'», en Las Provincias, M. C. A., 11/08/2005, p. 54 .

33. Son las Academias de la Lengua de Argentina, Bolivia, Chile, Colombia, Costa Rica, Cuba, Ecuador, El Salvador, Guatemala, Honduras, México, Nicaragua, Paraguay, Perú, Puerto Rico, República Dominicana, República de Panamá, Uruguay y Venezuela. Además de estas 19 academias y de la Real Academia Española, forman parte de la Asociación de Academias de la Lengua Española la Academia Norteamericana de la Lengua Española, la de Filipinas y la de Guinea Ecuatorial.

34. Argentina, Bolivia, Chile, Colombia, Costa Rica, Cuba, Ecuador, El Salvador, Guatemala, Guinea Ecuatorial, Honduras, México, Nicaragua, Paraguay, Perú, República Dominicana, República de Panamá, Uruguay, Venezuela y España. 
acordaron que Don Quijote sería el invitado de honor de todas las ferias del libro que se celebrasen en 2005 dentro de sus respectivos territorios.

Hubo, además, un intercambio de actividades entre ambas orillas del Atlántico, puesto que varias iniciativas españolas viajaron hasta Hispanoamérica y viceversa. Entre las primeras, destacan la representación «Quijote» de la compañía valenciana de títeres Bambalina Titelles, que desembarcó en Lima (Perú) en junio de 2005 y las obras del Teatro de la Zarzuela estrenadas en el 33 Festival Internacional Cervantino de Guanajuato (México), en octubre de 2005. Las piezas, una zarzuela con música de Ruperto Chapí («La venta de Don Quijote») y una ópera de Manuel de Falla («El Retablo de Maese Pedro»), se representaron en una gira que recorrió buena parte de México.

En cuanto a las iniciativas culturales que llegaron a España procedentes de Hispanoamérica, aparecen dos relacionadas de nuevo con las artes escénicas. Por un lado, el Ballet Nacional de Cuba estuvo de gira por toda España durante 2005 con «Don Quijote», dirigido por Alicia Alonso. Por otro, ocho compañías de Iberoamérica ${ }^{35}$ ofrecieron su visión teatral del Quijote durante los días 22 de junio y 10 de julio de 2005 en el «Festival de Teatro. El Quijote en Iberoamérica», de Madrid. Fue una iniciativa coordinada por la Sociedad Estatal de Conmemoraciones Culturales, la Casa de América, el Ayuntamiento y la Comunidad de Madrid.

En este punto es necesario que nos detengamos en las celebraciones que tuvieron lugar en Guanajuato (México), la única ciudad «cervantina» de América para la Unesco en ese momento ${ }^{36}$. Con motivo de la efeméride, España fue la invitada de honor del 33 Festival Cervantino de Guanajuato. Podemos aproximarnos a la notable magnitud de este festival y a su gran calado en la población de la ciudad leyendo el comienzo de esta crónica publicada por $E l$ Mundo durante el festival:

\begin{abstract}
Alonso Quijano se plantó ayer en México adarga en mano y se topó, para su sorpresa, con una ciudad repleta de sí mismo. En las plazas, ocho pétreos Quijotes de piedra y metal observaban a la concurrencia. En las calles, multitud de dobles del hidalgo posaban para los turistas. En las camisetas de los chicos, en las cantinas, su propia efigie, incluida la escupidera en la cabeza y la armadura desdentada, reinaba junto a, por ejemplo, iconos del rock $^{37}$.
\end{abstract}

35. El Mirón Cubano (Cuba), Teatro Núcleo (Argentina-Italia), Malayerba (Ecuador), Rubén Pagura (Costa Rica), Perro Teatro (México), Pia Fraus (Brasil), Companhia do Chapito (Portugal) y La Candelaria (Colombia). Vid. Luciano García Lorenzo, «Don Quijote en la escena española (2005). De la comicidad al testimonio político», en Tus obras los rincones de la tierra descubren. Actas del VI Congreso internacional de la Asociación de cervantistas. Alcalá de Henares, Asociación de Cervantistas-Centro de estudios cervantinos, 2008, pp. 15-27.

36. Así fue declarada por la Unesco en 2004. En enero de 2007, dicho organismo nombró a Azul (Argentina) la segunda ciudad cervantina de América.

37. «El Quijote se viste de zarzuela en la capital cervantina de Latinoamérica», en El Mundo, Quico Alsedo, 22/10/2005. 
Además de este festival, la ciudad cobija el Museo Iconográfico del Quijote, con más de 800 piezas, fundado en 1987 a instancias de Eulalio Ferrer ${ }^{38}$, el que fuera presidente de la Fundación Cervantina de México y el Centro de Estudios Cervantinos de México. En 2004 y 2005 distintos políticos del Ejecutivo de Castilla-La Mancha viajaron hasta Guanajuato para promocionar el IV Centenario del Quijote. En uno de esos viajes, José María Barreda, presidente de Castilla-La Mancha, fue nombrado «Huésped distinguido» de la ciudad. La Comisión de Guanajuato para la celebración del IV Centenario programó un total de 182 actividades a lo largo de 2005.

Brevemente, vamos a citar las iniciativas propiamente americanas y desarrolladas en la otra orilla del Atlántico recogidas por los periódicos analizados para rendir tributo a la novela: en Cuba, organizaron una muestra en la Biblioteca Nacional, titulada «Tras las huellas del Quijote», celebraron un seminario cervantino, bajo el nombre «Yo sé quién soy. El Quijote y la dimensión imperativa de la persona», e inauguraron un sitio web, llamado «La aventura cubana del Quijote» ${ }^{39}$; Colombia proclamó 2005 el Año del Quijote; en México, dejando al margen a Guanajuato, ciudad a la que ya nos hemos referido, se celebró una exposición, «Ex libris mundi», de cuarenta artistas nacionales con obras inspiradas en Don Quijote, el Ayuntamiento de la ciudad de Nezahualcoyotl (México) obligó a sus 1.200 policías a que leyeran la novela, el Gobierno nacional mexicano regaló un millón de ejemplares de la novela a maestros de las escuelas públicas, actividad también llevada a cabo por el Gobierno de Venezuela, que regaló un millón de ejemplares, en este caso a toda la población.

Por último, queremos citar dos iniciativas, recogidas en la prensa analizada, que supusieron entregas gratuitas de miles de ejemplares de la novela a dos países hispanoamericanos por parte de España. La Comunidad de Madrid entregó a Álvaro Uribe, presidente de Colombia, 50.000 ejemplares de la novela de Cervantes para que los repartiera en las escuelas de su país, algo similar a lo que hizo el Gobierno de España, que donó a las bibliotecas municipales de Cuba más de 400 ejemplares del Quijote.

Las variopintas actividades que acabamos de señalar, en países como México, Venezuela o Cuba, que fueron las que recogió la prensa española como si representaran la totalidad de las celebraciones de Hispanoamérica, no fueron

38. Para muchos es el padre del cervantismo moderno en México. Eulalio Ferrer fue un periodista español que se marchó a México en el exilio, donde residió el resto de su vida y trabajó como periodista y publicista. Sintió verdadera pasión por Cervantes y su magna novela, lo que explica que donase al Museo Iconográfico del Quijote de Guanajuato buena parte de sus fondos particulares y que fuese el gran impulsor de las principales iniciativas mexicanas de los últimos años que han tenido que ver con Cervantes y su novela. Su entrega cervantina explica que en la Feria Internacional del Libro de Guadalajara (México) de 2005 le rindiesen un merecido homenaje como bibliófilo («Eulalio Ferrer, el soldado que prefirió el Quijote», en El País, Juan Cruz, 29/11/2005).

39. La dirección de dicho sitio web es la siguiente: http://www.bnjm.cu/quijote. Por desgracia, actualmente está desactivada. Desconocemos si en 2015, con motivo de las celebraciones del IV Centenario de la publicación de la segunda parte del Quijote, las autoridades cubanas volverán a activar dicho portal web. 
las únicas que se celebraron allí en $2005^{40}$, lo que pone de manifiesto que los diarios analizados no realizaron una cobertura exhaustiva o completa sobre la efeméride al otro lado del Atlántico.

Tras concluir el recorrido por las actividades americanas recogidas en los diarios, vamos a tratar de extraer el valor simbólico que ostentó el personaje del Quijote en 2005 en Hispanoamérica. Para ello, resulta conveniente que prestemos atención a diferentes declaraciones de personas ilustres en relación con el Quijote y América. En primer lugar, destaca la opinión del escritor mexicano Jorge Volpi, quien considera que el Quijote es la base de la novela hispanoamericana.

Para nosotros, Cervantes es el fundador de nuestra literatura moderna, toda la novela hispanoamericana le debe muchísimo a Cervantes, sobre todo en los últimos años en que la novela ha alcanzado un grado de madurez enorme, a partir de la lectura directa sobre El Quijote hecha por todos los escritores $^{41}$.

El escritor, por tanto, huye de simbolismos o visiones esotéricas y resalta el valor literario de la novela para todos los escritores hispanoamericanos. Otra declaración de interés, muy distinta a la de Volpi, pertenece a Juan Carlos Romero Hicks, por aquel entonces gobernador del Estado de Guanajuato. Éste sí que ve en el Quijote un símbolo, en concreto, de la justicia; ve en el personaje un auténtico modelo a seguir.
A México y a España les une su idioma y cultura, y a Castilla-La Mancha y Guanajuato todo esto, la obra de Cervantes y los mismos anhelos, de- rrotar los molinos de viento para vivir en un mundo más justo y honesto. Sólo trabajando para los demás tendremos una visión más digna como humanidad ${ }^{42}$.

40. Entre las actividades valiosas que han dejado al margen los diarios analizados, José Montero Reguera (Universidad de Vigo) destaca «El Quijote en Buenos Aires», un congreso internacional organizado por la Asociación de Cervantistas, que él preside, en la capital de Argentina del 20 al 23 de septiembre de 2005 (entrevista telefónica a José Montero Reguera, 28/06/2010). José Manuel Lucía Megías (Universidad Complutense), por su parte, subraya una exposición organizada en Azul (Argentina) a finales de 2004, con motivo de la efeméride:

En Hispanoamérica no hubo la fiebre quijotesca que padeció España. Allí todo fue mucho más relajado. Entre todas las exposiciones que se llevaron a cabo, yo destacaría la labor de la ciudad de Azul, una población en decadencia en el corazón de la Pampa que consiguió, a raíz de poseer una notable biblioteca cervantina, organizar de la nada una exposición brillante en 2004 [«Exposición Cervantes», del 18 al 25 de noviembre en el Teatro Español], cuyo resultado fue que en 2007 fuera nombrada por la UNESCO «ciudad cervantina». En 2005 se celebraron en Azul las primeras jornadas cervantinas, que continúan año tras año. En esta ciudad toda la sociedad se vuelca con Cervantes porque ven en él una forma de desarrollo cultural y, por ende, social y económico. Es algo admirable (entrevista personal a Lucía Megías, 23/06/2010).

41. «Hispanistas americanos inician actos cervantinos», en Córdoba, Efe, 28/09/2004, p. 58.

42. «Castilla-La Mancha y Guanajuato estrechan lazos sobre 'El Quijote'», en La Tribuna de Ciudad Real, Redacción, 28/11/2005, p. 23 
Por otro lado, destaca el testimonio de Lisandro Otero, el que fuera entonces director de la Academia Cubana de la Lengua. Para Otero, el espíritu del Quijote se encuentra en la base de la independencia americana pues este reside en diferentes libertadores del continente.

[Don Quijote] es un idealista abrumado por su nobleza de espíritu. Rechaza el absurdo de una sociedad donde los cuerdos pasan por orates. Espíritu similar es el que animó a los libertadores americanos de Bolívar a Hidalgo y Louverture, de Martí a Artigas y San Martín y O’Higgins ${ }^{43}$.

Esta visión de Otero se aleja completamente del valor literario de la novela y, sobre todo, de la unión de la obra con España y, por ende, con Hispanoamérica gracias a los lazos políticos, culturales y sociales que se establecieron entre ambas en el pasado. En esta línea se sitúa una declaración de Hugo Chávez, presidente de Venezuela: «Todos nosotros vamos a leer El Quijote para nutrirnos aún más del espíritu de un luchador que quería deshacer entuertos y arreglar el mundo. Somos, en cierto modo, adeptos de Don Quijote» ${ }^{\square}$

Tal y como le ocurría a Otero, Chávez también se olvida de España al referirse a la novela y a su protagonista. Para él, el Quijote es un héroe universal, un modelo a seguir por su carácter luchador, sin padres ni madres a los que deber nada.

Como contrapunto a estas dos últimas visiones que no hacen referencia al origen español de la novela, queremos recoger unas declaraciones del presidente José Luis Rodríguez Zapatero, quien concibió la celebración del IV Centenario de la publicación de la primera parte de la novela como una oportunidad de integración de los pueblos.

Celebrar El Quijote supone fomentar el carácter de la cultura como elemento de integración de los pueblos y, también, sostener abiertamente que en El Quijote se pueden encontrar los principios y valores que permiten luchar a favor de la libertad, del progreso y de la dignidad del hombre ${ }^{44}$.

Aunque Rodríguez Zapatero no cita textualmente a Hispanoamérica, podemos suponer que se está refiriendo a ella, puesto que su declaración se integra en el discurso que pronunció con motivo de la reunión del Comité de Honor de la Comisión del IV Centenario, de la que formaban parte una veintena de ministros de Cultura americanos. Vemos, además, que para el presidente, el Quijote es un símbolo de la libertad, el progreso y la dignidad.

Por último, queremos detenernos en el testimonio de Pablo Caruana, responsable en 2005 del Teatro de Casa de América, en Madrid. Según él, «la visión que el Quijote ha suscitado en Latinoamérica suele reflejar una gran

43. «Don Quijote en América», en $A B C$, Lisandro Otero, 22/01/2005, p. 63.

44. «Zapatero invita a Iberoamérica a una celebración integradora del 'Quijote'», en La Voz de Galicia, Miguel Lorenci, 28/10/2004, p. 54. 
carga política $\rangle^{45}$. Caruana se refiere a las obras representadas en el citado «Festival de Teatro. El Quijote en Iberoamérica», donde participaron compañías latinoamericanas con montajes inspirados en el Quijote que reflejaban, por ejemplo, la lucha de unos presos políticos de la dictadura argentina que consiguen no sucumbir gracias a la novela o una reflexión sobre los atentados del 11-S y sus consecuencias.

\section{CONCLUSIONES}

A lo largo de nuestro estudio hemos observado cómo la visión que se tuvo en Hispanoamérica de la novela y de su personaje como símbolo fue muy distinta en el año 2005 a la de 1905. En el primer periodo, se vio en el Quijote un nexo con la antigua metrópoli, por la que se sentía admiración, o, incluso, gratitud por un pasado y, sobre todo, un idioma común. La novela de Cervantes era, por tanto, un símbolo de orgullo para todos pero a la vez un elemento claramente español.

Mientras que en 1905 se produjo una visión unitaria y homogénea respecto al Quijote y la novela, en 2005, en cambio, predominó la heterogeneidad en cuanto al significado de ambos en Sudamérica. Hubo intelectuales como Jorge Volpi que destacaron el valor literario universal de la obra, considerada por el escritor como la base de la novela hispanoamericana. Otros, en cambio, resaltaron el papel de libertador o héroe del Quijote, dejando a un lado su valor literario o sus lazos con España. Como observamos, en ambas posturas el origen español de la obra y de su protagonista fue olvidado o quedó relegado a un segundo plano.

Si nos detenemos en las actividades conmemorativas sudamericanas, podemos concluir que buena parte de las celebradas en 2005, principalmente las oficiales, buscaron una mayor lectura de la novela por parte de la sociedad, a través de la publicación de ediciones populares de la obra, mediante el nombramiento del Quijote como protagonista de diferentes ferias del libro o con el obsequio de ejemplares de la novela entre la población. En este sentido, prevalece el valor literario de la obra y su difusión en la sociedad. En 1905, en cambio, las actividades americanas fueron, a tenor de lo leído en la prensa española, más elitistas, en forma de veladas o concursos literarios, con una escasa difusión de la novela en el pueblo.

Queremos concluir este estudio con la conclusión más importante que extraemos de este, desde nuestro punto de vista. En nuestra opinión, la cobertura que se realizó tanto en 1905 como en 2005 de las celebraciones quijotescas en Hispanoamérica fue, a todas luces, deficiente. La escasez de medios técnicos y humanos podría justificar de algún modo el escaso número de informaciones

45. «Ocho compañías de Iberoamérica ofrecen su visión teatral del 'Quijote'», en El País, K. Cabrera, 17/06/2005. 
que publicaron los diarios españoles en el primer periodo, ya que en aquella época resultaba costoso y complicado contar con corresponsales en las ciudades más importantes de Sudamérica. Además, el escaso número de páginas de los diarios de principios de siglo XX, que solía rondar las cuatro páginas, también explica que los periódicos estudiados no incluyeran un volumen abultado de informaciones sobre el extranjero.

Sin embargo, no encontramos justificación posible en la cobertura de 2005 . Ese año, el uso de Internet estaba completamente extendido en las redacciones de los diarios españoles, lo que facilitaba de forma considerable, en términos económicos, el envío de textos desde cualquier lugar del mundo, y las agencias de noticias cubrían prácticamente cada punto del globo. Por ello, a tenor de nuestro estudio, pensamos que si el número de informaciones sobre el IV Centenario en Hispanoamérica resultó escaso fue porque este tema no interesaba a los diarios españoles.

A nuestro modo de ver, esto supone un claro menosprecio a los países del otro lado del Atlántico, a los que estamos unidos por un pasado y una lengua común. Recordemos que en 1605 la novela no sólo se podía leer en España, pues ese mismo año llegó al Nuevo Mundo en las bodegas de varios barcos españoles. En el pasado de Sudamérica, en sus raíces, también vive el Quijote, lo que explica las numerosas y ricas celebraciones que tuvieron lugar en el IV Centenario de la publicación de la novela, actividades de las que la prensa española sólo recogió unas migajas, absorbida como estaba por la vorágine de los festejos nacionales.

\section{BIBLIOGRAFÍA}

Cervantes y Saavedra, Miguel de (1905). Del Ingenioso Hidalgo Don Quijote de la Mancha: Tricentenario de sua primeira edição: Sessão commerantiva pela Academia Real das Sciencias de Lisboa em 9 de Maio de 1905. Lisboa: Typographia da Academia.

Chaparro Domínguez, María Ángeles (2008). «El diario El País ante el IV Centenario del Quijote», Espéculo, revista cuatrimestral de estudios literarios. 40, http://www.ucm. es/info/especulo/numero40/quipais.html [fecha de consulta: 30/06/2011].

Chaparro Domínguez, María Ángeles (2009). «La prensa española ante el IV Centenario de la publicación de la primera parte del Quijote (2005)», Anales Cervantinos. 41, pp. 285-315. Enciclopedia universal ilustrada europeo-americana (1908-1930). Barcelona: Espasa-Calpe, t. 12, p. 1379.

Lucía Megías, José Manuel (2006). «Catálogos de las ediciones del Quijote (notas para un balance de las publicaciones del IV Centenario)», Anales Cervantinos. 38, pp. 271-277.

Meléndez Valdés, Juan (1974). Las bodas de Camacho el Rico: comedia pastoral premiada por la villa de Madrid, para representar en el Teatro de la Cruz con motivo de los festejos públicos que executa por el feliz nacimiento de los serenísimos infantes Cárlos y Felipe y ajuste definitivo de la paz. Madrid: Joachin Ibarra.

Montero Reguera, José (1992). «La recepción del Quijote en Hispanoamérica (Siglos XVII al XIX)», Cuadernos Hispanoamericanos. 500, pp. 132-140. 
Montero Reguera, José (2006). «El Quijote en Hispanoamérica», en Héctor Brioso Santos, Cervantes y América. Madrid: Marcial Pons, pp. 317-343.

Sawa, Miguel; Becerra, Pablo (1905). Crónica del Centenario del Don Quijote. Madrid: Establecimiento tipográfico de Antonio Marzo.

Zulueta, Ignacio M. (1984). «La tradición cervantina (algunos aspectos de la proyección del Quijote en Hispanoamérica)», Anales Cervantinos. 22, pp. 143-157.

\section{BIBLIOGRAFÍA ADICIONAL}

\section{Periódicos}

$A B C$, Madrid, 1904-1905 y 2004-2005, http://www.abc.es/hemeroteca [fecha de consulta: octubre 2010].

Córdoba, Córdoba, 2004-2005, http://www.diariocordoba.com/noticias/hemeroteca.asp [fecha de consulta: septiembre 2010].

Deia, San Sebastián, 2004-2005, http://www.deia.com/es/buscador [fecha de consulta: septiembre 2010].

El Correo de Guipúzcoa, San Sebastián, 1904-1905, http://liburutegidigitala.donostiakultura.com/Liburutegiak/catalogo_archivo.php?dp_id=116 [fecha de consulta: octubre 2010].

El Imparcial, Madrid, 1904-1905.

El Liberal, Madrid, 1904-1905.

El Liberal de Sevilla, Sevilla, 1904-1905.

El Mundo, Madrid, 2004-2005, http://ariadna.elmundo.es/buscador/archivo.html [fecha de consulta: noviembre 2010].

El País, Madrid, 2004-2005, http://www.elpais.com/archivo/buscando.html [fecha de consulta: octubre 2010].

La Correspondencia de España, Madrid, 1904-1905.

La Crónica, Guadalajara, 1904-1905, http://bidicam.jccm.es/i18n/publicaciones/numeros por_mes.cmd?idPublicacion=10876 [fecha de consulta: noviembre 2010].

La Crónica de Guadalajara, Guadalajara, 2004-2005, http://www.lacronica.net/frontend/ lacronica/otros_buscadores.php [fecha de consulta: noviembre 2010].

La Tribuna de Ciudad Real, Ciudad Real, 2004-2005.

La Vanguardia, Barcelona, 1904-1905 y 2004-2005, http://www.lavanguardia.es/hemeroteca/ [fecha de consulta: diciembre 2010].

La Voz de Galicia, A Coruña, 1904-1905 y 2004-2005, http://www.lavozdegalicia.es/SSEE/ buscavoz/resultados.jsp [fecha de consulta: septiembre 2010].

Las Provincias, Valencia, 1904-1905 y 2004-2005, http://www.lasprovincias.es/valencia/ hemeroteca [fecha de consulta: agosto 2010].

Levante-EMV, Valencia, 2004-2005, http://www.levante-emv.com/servicios/hemeroteca/ hemeroteca.jsp [fecha de consulta: agosto 2010].

Páginas web y otras fuentes

Encyclopedia Britannica, http://www.britannica.com/EBchecked/topic/86359/AntonioSanchez-de-Bustamante-y-Sirven, [fecha de consulta: 14/07/2011].

«La aventura cubana del Quijote», http://www.bnjm.cu/quijote [fecha de consulta: $14 / 07 / 2011]$. 
Lucía Megías, José Manuel. Entrevista personal (23/06/2010).

Montero Reguera, José. Entrevista telefónica (28/06/2010).

Oficina de Justificación de la Difusión, http://www.ojd.es/OJD/Portal/diarios ojd/_4DOSpuiQo1Y_FOivPcLIIA [fecha de consulta: 15/07/2011].

Secretaría de Cultura, Artes y Deportes de la República de Honduras, http://www.scad.gob. $\mathrm{hn} /$ index.php?option $=$ com_content\&task=view\&id=39\&Itemid=84 [fecha de consulta: $14 / 07 / 2011]$.

Recibido: 21 de julio de 2011

Aceptado: 1 de junio de 2012

\title{
Resumen
}

En este artículo se analiza la cobertura que brindó la prensa española a las celebraciones organizadas en Hispanoamérica con motivo del III y el IV Centenario de la publicación de la primera parte del Quijote, efemérides que tuvieron lugar en 1905 y 2005, respectivamente. El estudio de un total de veintiuna cabeceras, entre las que figura El Imparcial, El Liberal o La Correspondencia de España, del primer periodo, y El País, El Mundo o La Vanguardia del segundo, nos permitirá averiguar cómo se vivieron ambos centenarios en Hispanoamérica, qué importancia tuvieron en la prensa estos homenajes y, además, podremos extraer el carácter simbólico concreto que adquirió el hidalgo manchego en uno y otro periodo.

Palabras clave: Quijote; III Centenario (1905); IV Centenario (2005); Hispanoamérica; Prensa.

Title: Celebrations III and IV Centenary of Don Quixote in Spanish America through the Spanish press from 1905 to 2005

\begin{abstract}
This article analyzes the coverage that the Spanish press provided to Spanish American celebrations for the Third and Fourth Centenary of the publication of the first part of Don Quixote, events that took place in 1905 and 2005, respectively. By the study of a total of twenty-one newspapers, which include El Imparcial, El Liberal and La Correspondencia de España, of the first period, and El País, El Mundo and La Vanguardia of the second, we will find out how they lived both centenaries in Spanish America, how important were these tributes in the press and, furthermore, we will know the concrete symbolic meaning that the popular Spanish nobleman acquired in either period.
\end{abstract}

Key words: Don Quixote; Third Centenary (1905) ; Fourth Centenary (2005); Spanish America; Press. 